\title{
Structural brain differences in school-age children with and without single-suture craniosynostosis
}

\author{
Kristina Aldridge, PhD, ${ }^{1}$ Brent R. Collett, $\mathrm{PhD},{ }^{2-4}$ Erin R. Wallace, $\mathrm{PhD},{ }^{3}$ Craig Birgfeld, MD, ${ }^{4}$ \\ Jordan R. Austin, BS, BSN, ${ }^{1}$ Regina Yeh, MSW, ${ }^{5}$ Madison Feil, BS, ${ }^{5}$ \\ Kathleen A. Kapp-Simon, PhD, ${ }^{6,7}$ Elizabeth H. Aylward, PhD, ${ }^{3,5}$ Michael L. Cunningham, MD, PhD, ${ }^{4}$ \\ and Matthew L. Speltz, PhD ${ }^{2-4}$
}

'Department of Pathology \& Anatomical Sciences, University of Missouri School of Medicine, Columbia, Missouri; ${ }^{2 D e p a r t m e n t ~}$ of Psychiatry and Behavioral Sciences, University of Washington; ${ }^{3}$ Center for Child Health, Behavior, and Development, and ${ }^{5}$ Center for Integrative Brain Research, Seattle Children's Research Institute; ${ }^{4}$ Seattle Children's Craniofacial Center, Seattle Children's Hospital, Seattle, Washington; ${ }^{6}$ Department of Surgery, Northwestern University; and ${ }^{7}$ Shriner's Hospital for Children, Chicago, Illinois

OBJECTIVE Single-suture craniosynostosis (SSC), the premature fusion of a cranial suture, is characterized by dysmorphology of the craniofacial skeleton. Evidence to suggest that children with SSC are at an elevated risk of mild to moderate developmental delays and neurocognitive deficits is mounting, but the associations among premature suture fusion, neuroanatomy, and neurocognition are unexplained. The goals of this study were to determine 1) whether differences in the brain are present in young children with the 2 most common forms of SSC (sagittal and metopic) several years following surgical correction, and 2) whether the pattern of differences varies by affected suture (sagittal or metopic). Examination of differences in the brains of children with SSC several years after surgery may illuminate the growth trajectory of the brain after the potential constraint of the dysmorphic cranium has been relieved.

METHODS The authors compared quantitative measures of the brain acquired from MR images obtained from children with sagittal or metopic craniosynostosis $(n=36)$ at 7 years of age to those obtained from a group of unaffected controls $(n=27)$ at the same age. The authors measured the volumes of the whole brain, cerebral cortex, cerebral white matter, cerebral cortex by lobe, and ventricles. Additionally, they measured the midsagittal area of the corpus callosum and its segments and of the cerebellar vermis and its component lobules. Measurements obtained from children with SSC and controls were compared using linear regression models.

RESULTS No volume measures of the cerebrum or of the whole brain differed significantly between patients with SSC and controls $(p>0.05)$. However, ventricle volume was significantly increased in patients with SSC ( $p=0.001)$, particularly in those with sagittal craniosynostosis $(p<0.001)$. In contrast, the area of the corpus callosum was significantly reduced in patients with metopic synostosis $(p=0.04)$, particularly in the posterior segments $(p=0.004)$. Similarly, the area of lobules VI-VII of the cerebellar vermis was reduced in patients with SSC ( $p=0.03)$, with those with metopic craniosynostosis showing the greatest reduction $(p=0.01)$.

CONCLUSIONS The lack of differences in overall brain size or regional differences in the size of the lobes of the cerebrum in children with metopic and sagittal synostosis suggests that the elevated risk of neurodevelopmental deficits is not likely to be associated with differences in the cerebral cortex. Instead, this study showed localized differences between sagittal and metopic craniosynostosis cases as compared with controls in the ventricles and in the midsagittal structures of the corpus callosum and the cerebellum. It remains to be tested whether these structural differences are associated with the increased risk for developmental delay and neurocognitive deficits in children with SSC.

https://thejns.org/doi/abs/10.3171/2016.9.PEDS16107

KEY WORDS craniosynostosis; brain; MRI; development; craniofacial 
$\mathrm{S}$ INGLE-SUTURE craniosynostosis (SSC) is defined by the premature fusion of one of the cranial sutures, including the sagittal, metopic, right or left coronal, or right or left lambdoid. Across all sutures, SSC occurs in roughly 1 in 2000 live births. ${ }^{18,36}$ The diagnostic phenotype of SSC is characterized by dysmorphology of the craniofacial skeleton, confirmed by radiographic evidence of a closed suture. The idea that single-suture fusions might compromise neurodevelopment has been discussed for many years. Numerous studies of children with SSC both prior to and following surgical intervention suggest an elevated risk of mild to moderate developmental delays. ${ }^{19,21,57-59}$ However, the prevalence of abnormal brain findings on MRI is very low, ${ }^{30}$ leaving the association between premature suture fusion and neurocognition unexplained. . $^{30,32,50,54,56,69}$

In an effort to develop more focused hypotheses about the relation between craniosynostosis and neurodevelopment, we examined quantitative measures of the brain among children diagnosed and treated for SSC in relation to a comparison group of unaffected controls. We followed to age 7 years a large sample of infants with SSC who were recruited and assessed prior to corrective surgery. We included children diagnosed with the 2 most common forms of SSC: sagittal craniosynostosis and metopic craniosynostosis. We assessed overall and regional volume and area measures of the brain on high-resolution MRI scans to determine whether differences in the brain are present in young children with sagittal or metopic craniosynostosis several years following surgical correction and whether the pattern of differences varies by affected suture (sagittal or metopic). Examination of differences in the brains of children with SSC several years after surgery may illuminate the growth trajectory of the brain after the potential constraint of the dysmorphic cranium has been relieved. Neuroanatomical abnormalities may be present in at least some individuals with SSC long after surgical correction of the cranial abnormality. For example, Beckett et al. ${ }^{8}$ observed abnormal anatomical connectivity among regions of the brain in a small sample of adolescents diagnosed and treated for sagittal synostosis in infancy.

In addition to obtaining volumetric measures of the whole brain, gray and white matter of the cerebral lobes, ventricles, and subarachnoid space, we measured the midsagittal area of the corpus callosum and of the cerebellar vermis. Previous qualitative assessments have noted anomalies of the corpus callosum in children with metopic synostosis, ${ }^{11}$ and in other populations a reduction in corpus callosum area has been correlated with mild neurodevelopmental problems like those observed in children with SSC. ${ }^{22,50,71}$ Although there is no specific evidence suggesting alteration in the cerebellar vermis in SSC, this structure is frequently abnormal in children without SSC who have similar developmental disorders, including dyslexia,${ }^{24}$ other language and/or speech disorders, ${ }^{51,62}$ and motor deficits. ${ }^{9,42}$ Furthermore, Type I Chiari malformations have been observed in a small number of SSC cases $^{30,65}$ and in cases of metopic ridging. ${ }^{66}$

\section{Methods \\ Participants}

We used cross-sectional MRI data collected as part of a school-age neuropsychological assessment of children with SSC and unaffected children ("controls"), who had been followed since infancy in a longitudinal study. ${ }^{58} \mathrm{In}$ the original, "parent" study, we enrolled all eligible children with SSC between January 2002 and September 2006 from the following sites: Seattle Children's Hospital; the Cleft Lip and Palate Institute and Northwestern University in Chicago; Children's Healthcare of Atlanta; St. Louis Children's Hospital; and Children's Hospital of Philadelphia. Unaffected controls were recruited by each center and frequency-matched to cases at the time of recruitment. Participants were psychometrically assessed at a "baseline" visit that occurred, for patients with SSC, before surgery (mean age 7.4 months) and at 3 subsequent visits, at which the patients' average ages were 18 months, 36 months, and 7 years ("school age"); the last age point is the focus of this report. All recruitment and data collection procedures were performed with informed consent following IRB-approved protocols.

\section{Patients With SSC}

Infants with SSC were referred to the parent project at the time of their initial diagnosis by a treating surgeon or pediatrician. Infants were eligible if they: 1) had SSC (specifically, sagittal or metopic craniosynostosis), confirmed by CT; 2) had not yet had cranial vault surgery; and 3) were younger than 30 months at recruitment. Exclusion criteria included: 1) prematurity $(<34$ weeks gestation); 2) major medical or neurological conditions (cardiac defects, seizure disorders, significant health conditions requiring surgical correction, etc.); 3) presence of 3 or more extracranial minor malformations; ${ }^{16}$ or 4 ) presence of other major malformations. From among the cases involving patients recruited for the parent study who participated in the school-age assessment, ${ }^{56} 27$ families of children with a history of isolated sagittal craniosynostosis and 30 families of children with a history of isolated metopic craniosynostosis were also approached for participation in an MRI examination. Consent to attempt an MRI examination was obtained in 61 cases (23 sagittal and 18 metopic), all but one involving patients treated at Seattle Children's Hospital; the exception was a single patient who was treated at the Cleft Lip and Palate Institute in Chicago. This ultimately resulted in 22 and 15 successful scans obtained in sagittal and metopic cases, respectively (Table 1).

The patients' average ages at surgery were 5.2 and 10.5 months, respectively, for sagittal and metopic cases, with $19 \%$ and $13 \%$, respectively, needing subsequent surgical revision. With respect to type of surgery, a posterior vault modified pi procedure was performed in almost all cases of sagittal craniosynostosis (91\%) and fronto-orbital advancement was performed in all metopic cases. Among the intra- and postoperative events and complications we recorded from medical charts, ${ }^{44}$ low hematocrit $(<25 \%)$ was observed in $67 \%$ of both sagittal and metopic cases, and hypothermia $\left(<36^{\circ} \mathrm{C}\right)$ was observed in $11 \%$ and $19 \%$ of sagittal and metopic cases, respectively. Postoperative laboratory findings of coagulopathy were observed in $33 \%$ of both sagittal and metopic cases. Other more significant events and complications (air embolism, hypertension re- 
TABLE 1. Demographic characteristics of children with and without SSC at time of MRI acquisition

\begin{tabular}{ccccc}
\hline Variable & Controls $(\mathrm{n}=27)$ & SSC (all, $\mathrm{n}=36)$ & Sagittal $(\mathrm{n}=21)$ & Metopic $(\mathrm{n}=15)$ \\
\hline Mean age in yrs & $7.30(0.28)$ & $7.40(0.28)$ & $7.33(0.26)$ & $7.51(0.29)$ \\
\hline Sex & & & & $3(20.0)$ \\
\hline Female & $7(25.9)$ & $8(22.2)$ & $5(23.8)$ & $12(80.0)$ \\
\hline Male & $20(74.1)$ & $28(77.8)$ & $16(76.2)$ & $2(13.3)$ \\
\hline Race/ethnicity & & & & $13(86.7)$ \\
\hline Non-white & $6(22.2)$ & $6(16.7)$ & $17(81.0)$ & $2(13.3)$ \\
\hline White & $21(77.8)$ & $30(83.3)$ & & $8(53.3)$ \\
\hline SES† & & & $5(23.8)$ & $5(33.3)$ \\
\hline I (highest) & $6(22.2)$ & $7(19.4)$ & $4(19.9)$ & $0(0)$ \\
\hline II III & $17(63.0)$ & $17(47.2)$ & $3(14.3)$ & $0(0)$ \\
\hline IV & $3(11.1)$ & $9(25.0)$ & $0(0)$ & $3(8.3)$ \\
\hline V (lowest) & $1(3.7)$ & $0(0)$ & & \\
\hline
\end{tabular}

SES = socioeconomic status.

Data are presented as number of patients (\%) unless otherwise indicated. Means are presented with standard deviations.

* Includes Hispanic/Latino ethnicity, Asian/Pacific Islander, Black/African American, and mixed races or ethnicities.

† Using Hollingshead scale. ${ }^{29}$

quiring pressure/resuscitation, complete extubation) were rare, each occurring in no more than a single case.

\section{Controls}

Infants were eligible as controls for the parent study if they had no known craniofacial anomaly and met none of the exclusionary criteria for cases. Control group participants were recruited through pediatric practices, birthing centers, and announcements in publications of interest to parents of newborns. Controls were frequency-matched to cases on factors related to neurodevelopmental performance that may also be potential confounders: 1) age at enrollment (within \pm 3 weeks); 2) sex; 3 ) family socioeconomic status within the same Hollingshead category; ${ }^{29}$ and 4) race/ethnicity. For the MRI study, we selectively approached control group parents who had children participating in the school-age assessment and who best matched the age and sex of patients with SSC whose parents had already consented to an MRI. Twenty-seven such families consented to participate, resulting in 27 successful scans (Table 1).

\section{MRI Acquisition}

All MRI studies were performed using the 3.0-T Siemens Trio scanner at the Children's Hospital and Regional Medical Center in Seattle using the following protocol: T1weighted MPRAGE $1 \times 1 \mathrm{~mm}$ sagittal slices, $1 \mathrm{~mm}$ contiguous slice thickness, matrix $256 \times 256$, TE $3.43 \mathrm{msec}$, TR $7.39 \mathrm{msec}$, and flip angle $8^{\circ}$. All scans completed for inclusion in this study were reviewed by a radiologist for clinical anomalies that would require further assessment.

Children were not sedated but were instead desensitized to and coached to participate in the MRI procedure, along with a parent. Children were shown images of the MRI machine, the MRI room, and other same-aged children participating comfortably in the procedure. Noise- cancelling earphones were used to minimize noise, and the child was encouraged to select a favorite movie on DVD for viewing during the scan. During the MRI session, the child's head was secured with foam padding to help them remain still. Parents were allowed to stay in the scanning room with their child during the scan.

\section{Brain Volume Measures}

Volume measures were obtained from the MRI studies using Amira 5.4 software (Fig. 1). Amira allows the user to define a region of interest (ROI) through either automatic thresholding or manual delineation of individual voxels and then calculates volume (in $\mathrm{mm}^{3}$ ) from the image resolution parameters. ROIs were manually segmented from the MRIs by a single rater, blind to diagnosis. Whole brain volume (WBV) included the cerebral hemispheres, midbrain, cerebellum, and brainstem to an end plane defined through the foramen magnum. WBV did not include ventricles, venous sinuses, cranial nerves, or blood vessels. Ventricular volume (VV) included the lateral ventricles, third ventricle, cerebral aqueduct, and fourth ventricle. Cerebral cortical gray matter volume (CGV) was defined as the ROI including all cerebral cortex. Cerebral white matter volume (CWV) included all white matter within the CGV, not including cerebral peduncles. Frontal cortical gray matter volume (FGV) was defined as the ROI including cortical gray matter anterior to the central sulcus, superior to the sylvian fissure on the lateral surface, and superior and anterior to the cingulate sulcus on the medial surface. Temporal cortical gray matter volume (TGV) was defined as the ROI including cortical gray matter inferior to the sylvian fissure and anterior to a line drawn superoinferiorly through the preoccipital notch on the lateral and inferior surfaces. Parieto-occipital cortical gray matter volume (POGV) pertained to all cortical gray matter posterior to the central sulcus, superior to the sylvian fissure, and posterior to the temporal lobe as defined by the preoc- 


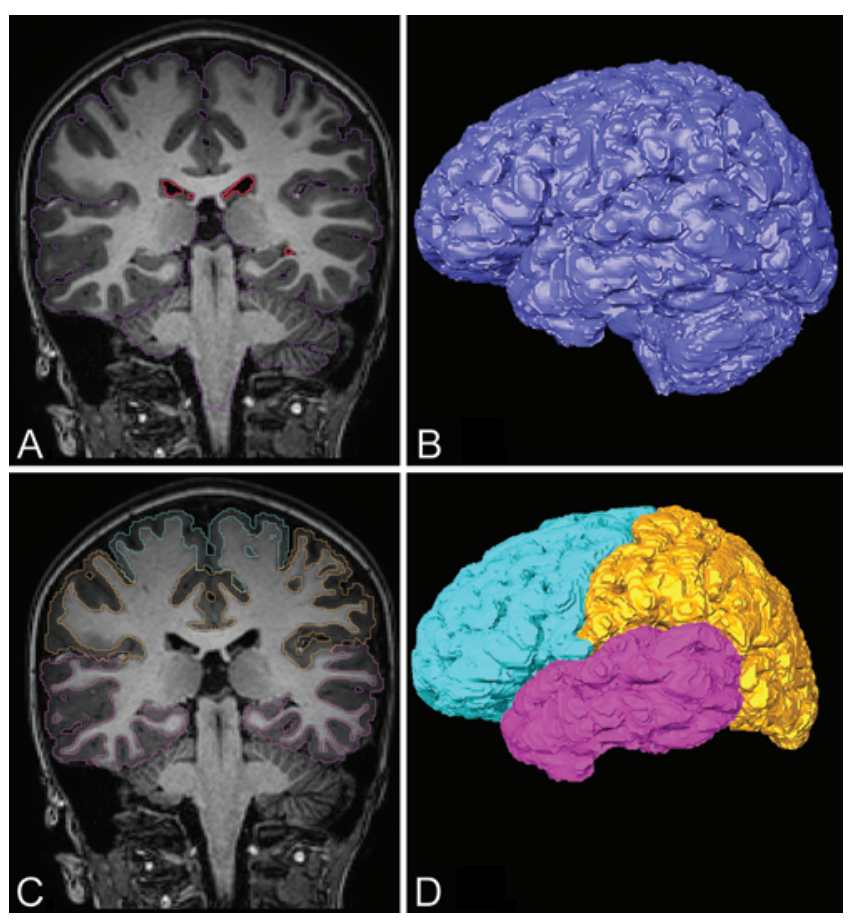

FIG. 1. Manual segmentation of ROIs in MR images. A and B: Whole brain volume (WBV) segmentation in coronal slice (A) and right lateral view of the $3 \mathrm{D}$ reconstruction (B). C and D: Segmentation of cerebral cortical gray matter by lobe in coronal slice $(\mathrm{C})$ and right lateral view of the 3D reconstruction (D). Purple indicates WBV; cyan, frontal cortical gray matter; gold, parieto-occipital cortical gray matter; pink, temporal cortical gray matter; and red, ventricles. Figure is available in color online only.

cipital notch line laterally. Volume measures could not be obtained for a subset of 12 MRI scans for various reasons, including localized motion artifacts and insufficient gray/ white contrast. Excellent intra-rater reliability for volume measures was established: interclass correlations between 2 trials by the same rater using a randomly selected subsample of 10 subjects were excellent (interclass correlation coefficient [ICC] 1.00 for WBV, ICC 0.99 for VV, and ICC 0.91 to 0.99 for the subregions of the cerebrum).

\section{Area Measures of the Corpus Callosum}

Area measures were performed on a PC graphics workstation, using MEASURE. ${ }^{6}$ Each scan was rotated in 3D space so that the axial images are parallel to the line connecting the anterior commissure (AC) and posterior commissure (PC) and perpendicular to the interhemispheric fissure (AC-PC plane). Measurements were made blind to diagnosis. The slice yielding the clearest visualization of the cerebral aqueduct was selected for the corpus callosum measures. The midsagittal area of the corpus callosum was drawn manually (Fig. 2). The length of the line connecting the most anterior and posterior points of the corpus callosum was then calculated and divided by 5 . Lines perpendicular to this line were drawn to divide the corpus callosum into 5 equal-length segments. The area of each of these segments was then determined. The midsagittal area of the cerebrum was also drawn to adjust for total brain size for these measures. Excellent inter-rater
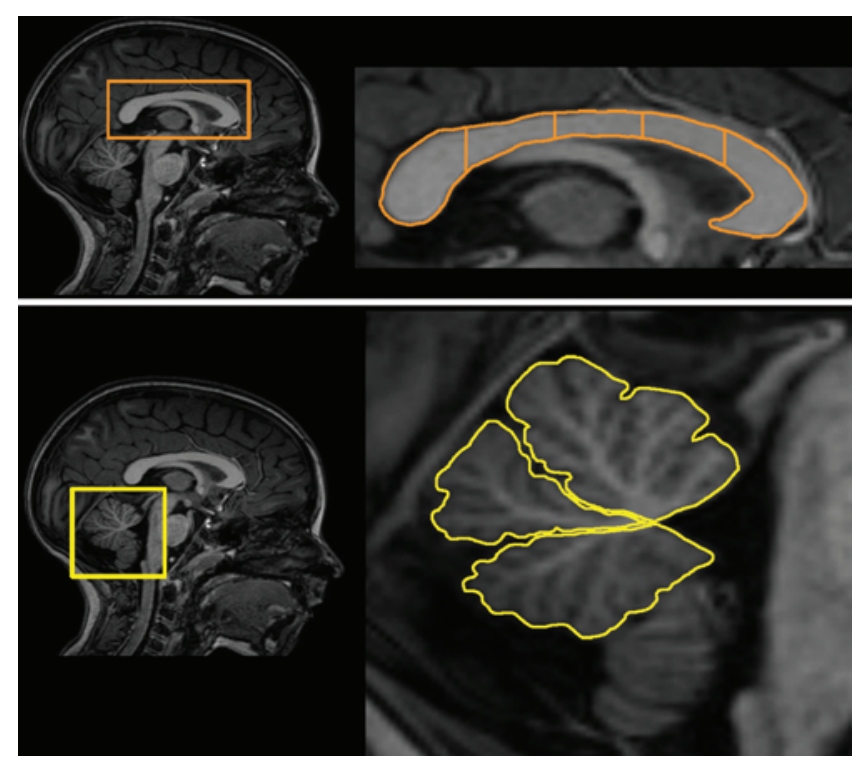

FIG. 2. Manual segmentation of midsagittal ROls in MR images. Upper: Corpus callosum segmentation. The anteroposterior length was used to divide the corpus callosum into 5 equal segments. Lower: Cerebellar vermis segmentation into anterior lobe, posterior lobules VI-VII, and posterior lobules VIII-X. Figure is available in color online only.

reliability for corpus callosum measurement was established (ICC 0.90).

\section{Area Measures of the Cerebellar Vermis}

Area measures of the vermis were measured on the midsagittal slice that bisected the cerebellar hemispheres. This was usually the same midsagittal slice used for the corpus callosum measures. However, in cases in which the hemispheric fissure was not perfectly straight, the brain was rotated and the midsagittal slice was redefined for the cerebellar vermis measures. Area was measured for the entire vermis on this midsagittal slice, and 3 subsections of the vermis, the anterior lobe (lobules I-V), the superior posterior lobe (lobules VI-VII), and the inferior posterior lobe (lobules VIII-X) (Fig. 2). Excellent interrater reliability for vermis measures was established (ICC 0.96 for total vermis, and ICC 0.95 to 0.98 for the subregions).

\section{Data Analyses}

The distributions of demographic characteristics, brain volume measures, and corpus callosum measures at 7 years of age were calculated for patients who had undergone craniosynostosis surgery and controls and by suture type. Linear regression with robust standard errors was used to estimate differences between the SSC group and controls and differences between suture type within cases with corresponding 95\% confidence intervals. All estimates were adjusted for age at the time of the MRI. Brain volume measures were additionally adjusted for whole brain volume, and corpus callosum and cerebellar area measures were adjusted for total midsagittal brain area. The control group was the referent category in analyses comparing all SSC cases to controls and each suture type to controls. The group of cases of sagittal craniosynostosis 
TABLE 2. Adjusted mean brain volumes $\left(\mathrm{cm}^{3}\right)$ for children with and without SSC

\begin{tabular}{|c|c|c|c|c|c|c|c|c|}
\hline \multirow[b]{2}{*}{ Variable } & \multicolumn{2}{|r|}{ Controls } & \multicolumn{2}{|r|}{ SSC (all) } & \multicolumn{2}{|r|}{ Sagittal } & \multicolumn{2}{|r|}{ Metopic } \\
\hline & $\mathrm{N}$ & Mean & $\mathrm{N}$ & Mean & $\mathrm{N}$ & Mean & $\mathrm{N}$ & Mean \\
\hline WBV & 19 & $1655.5 \pm 116.3$ & 30 & $1682.0 \pm 173.0$ & 18 & $1685.8 \pm 154.8$ & 12 & $1676.4 \pm 204.6$ \\
\hline CGV & 11 & $830.9 \pm 54.8$ & 22 & $860.2 \pm 78.6$ & 12 & $868.2 \pm 86.7$ & 10 & $850.5 \pm 71.0$ \\
\hline CWV & 11 & $613.8 \pm 66.8$ & 22 & $651.8 \pm 77.8$ & 12 & $654.0 \pm 56.7$ & 10 & $649.2 \pm 101.0$ \\
\hline FGV & 11 & $287.3 \pm 31.9$ & 22 & $284.4 \pm 33.0$ & 12 & $294.6 \pm 34.0$ & 10 & $272.2 \pm 28.6$ \\
\hline TGV & 11 & $147.9 \pm 9.9$ & 22 & $149.7 \pm 17.1$ & 12 & $150.9 \pm 16.3$ & 10 & $148.2 \pm 18.9$ \\
\hline POGV & 11 & $395.8 \pm 34.5$ & 22 & $426.1 \pm 60.1$ & 12 & $422.7 \pm 55.1$ & 10 & $430.1 \pm 68.5$ \\
\hline VV & 19 & $10.2 \pm 5.0$ & 30 & $16.7 \pm 8.3$ & 18 & $16.9 \pm 4.0$ & 12 & $16.5 \pm 12.5$ \\
\hline
\end{tabular}

$\mathrm{CGV}=$ cerebral cortical gray matter volume; $\mathrm{CWV}=$ cerebral white matter volume; FGV = frontal cortical gray matter volume; POGV = parietooccipital cortical gray matter volume; TGV = temporal cortical gray matter volume; VV = ventricular volume; WBV = whole brain volume.

Data were adjusted for age at MRI and whole brain volume (with the exception of WBV). Mean values are presented with standard deviations.

was the referent category in analyses involving only data from SSC cases. Using the estimated mean volumes for each group we also calculated the percentage difference in each measure. To examine whether results were influenced by adjusting for whole brain volume or total midsagittal brain area versus using ratios, all analyses of brain volume were repeated using the ratio of each measure to whole brain volume, without including an adjustment term for brain size. Analyses were repeated in a similar fashion for corpus callosum and cerebellar measures using the ratio of each measure to total midsagittal brain area. All analyses were performed using STATA version 12 (StataCorp LP). Because these are exploratory analyses, we did not adjust $p$ values for multiple comparisons. Instead, we evaluated the magnitude of the effect sizes and the precision of point estimates based on confidence intervals. ${ }^{25,49}$

\section{Results}

Age at the time of MRI was similar between the SSC group and controls and between the metopic and sagittal craniosynostosis subgroups (Table 1).

\section{Brain Volume Measures}

Adjusted mean volumes were calculated for each group (Table 2). Differences between the SSC group and controls were $2 \%$ or less for whole brain volume (WBV), cerebral cortical gray matter volume (CGV), cerebral white matter volume (CWV), frontal cortical gray matter volume (FGV), temporal cortical gray matter volume (TGV), and parieto-occipital cortical gray matter volume (POGV) (Tables 3-5). In contrast, large group differences were observed in ventricular volume (VV), with greater VV observed in SSC patients relative to controls $(89.5 \%$, absolute difference $5.6 \mathrm{~cm}^{3}, 95 \%$ CI 2.5-8.6, $\left.\mathrm{p}=0.001\right)$. VV was greatest in children with sagittal synostosis $(100 \%$ greater than controls, absolute difference $6.2 \mathrm{~cm}^{3}, 95 \%$ CI 3.3-9.2, $\mathrm{p}<0.001)$. VV was also greater in children with metopic synostosis relative to controls (69\%), although confidence intervals for group differences were wide and included the null (95\% CI -1.6 to $10.2, \mathrm{p}=0.16)$. Within the SSC group, differences in cerebral volume between the sagittal and metopic subgroups were small in magnitude, less than $10 \%$, with wide confidence intervals $(\mathrm{p}>0.05$ for all mea- sures). Results were not materially altered by sensitivity analyses using ratios of brain volume measures to whole brain volume (data not shown).

\section{Area Measures of the Corpus Callosum}

The adjusted mean midsagittal area of the corpus callosum overall and of 5 sections of the corpus callosum were calculated for each group (Table 6), with small group differences observed between SSC patients and controls, ranging from $2 \%$ to $13 \%$ (Tables $7-9$ ). The total corpus callosum area was decreased in SSC patients relative to controls (7\%, absolute difference $4.9 \mathrm{~cm}^{2}, 95 \%$ CI -9.7 to $-0.0, \mathrm{p}=0.05)$, particularly in the metopic subgroup (10\%, absolute difference $6.3 \mathrm{~cm}^{2}, 95 \%$ CI -12.0 to -0.6 , $\mathrm{p}=0.04)$. The area of all 5 segments was reduced in SSC patients compared with controls, with the greatest difference observed in corpus callosum segment 5 (CC S5; $13 \%$, absolute difference $2.3 \mathrm{~cm}^{2}, 95 \% \mathrm{CI}-4.1$ to $-0.6, \mathrm{p}$ $=0.01)$, particularly in the metopic subgroup $(16 \%$, absolute difference $3.0 \mathrm{~cm}^{2}, 95 \% \mathrm{CI}-4.9$ to $\left.-1.1, \mathrm{p}=0.004\right)$. Group differences in corpus callosum areas between the sagittal subgroup and controls and between the sagittal and metopic subgroups were small (differences ranged from less than $1 \%$ to $10 \%$ ), with none reaching statistical significance ( $\mathrm{p}$ values $>0.05$ ). Results did not differ when

TABLE 3. Adjusted group differences in mean brain volumes $\left(\mathrm{cm}^{3}\right)$ for children with and without SSC

\begin{tabular}{|c|c|c|c|c|c|}
\hline \multirow[b]{2}{*}{ Variable } & \multicolumn{2}{|c|}{ Mean Difference } & \multicolumn{2}{|c|}{$95 \% \mathrm{Cl}$} & \multirow{2}{*}{$\begin{array}{c}p \\
\text { Value }\end{array}$} \\
\hline & Absolute & $\%$ & LB & UB & \\
\hline WBV & 33.58 & $2.0 \%$ & -43.68 & 110.84 & 0.40 \\
\hline CGV & 2.82 & $0.4 \%$ & -20.24 & 25.87 & 0.81 \\
\hline CWV & 14.51 & $3.3 \%$ & -22.05 & 51.06 & 0.44 \\
\hline FGV & -8.11 & $-3.3 \%$ & -28.16 & 11.94 & 0.43 \\
\hline TGV & -1.87 & $-1.5 \%$ & -9.59 & 5.86 & 0.64 \\
\hline POGV & 12.79 & $4.6 \%$ & -12.97 & 38.55 & 0.34 \\
\hline VV & 5.56 & $89.5 \%$ & 2.50 & 8.62 & $0.001^{* *}$ \\
\hline
\end{tabular}

LB = lower bound; UB = upper bound.

Data were adjusted for age at MRI and whole brain volume (with the exception of WBV). The controls constitute the referent category. ** $p \leq 0.01$. 
TABLE 4. Adjusted group differences in mean brain volumes $\left(\mathrm{cm}^{3}\right)$ for children with SSC affecting different sutures (sagittal, metopic) and children without craniosynostosis (controls)

\begin{tabular}{|c|c|c|c|c|c|c|c|c|c|c|}
\hline \multirow[b]{3}{*}{ Variable } & \multicolumn{5}{|c|}{ Sagittal vs Controls } & \multicolumn{5}{|c|}{ Metopic vs Controls } \\
\hline & \multicolumn{2}{|c|}{ Mean Difference } & \multicolumn{2}{|c|}{$95 \% \mathrm{Cl}$} & \multirow{2}{*}{$\begin{array}{c}p \\
\text { Value }\end{array}$} & \multicolumn{2}{|c|}{ Mean Difference } & \multicolumn{2}{|c|}{$95 \% \mathrm{Cl}$} & \multirow{2}{*}{$\begin{array}{c}p \\
\text { Value }\end{array}$} \\
\hline & Absolute & $\%$ & LB & UB & & Absolute & $\%$ & LB & UB & \\
\hline WBV & 31.07 & $1.9 \%$ & -57.88 & 120.03 & 0.50 & 38.25 & $2.3 \%$ & -83.34 & 159.84 & 0.54 \\
\hline CGV & 6.25 & $1.0 \%$ & -22.78 & 35.28 & 0.68 & -1.57 & $-0.2 \%$ & -25.47 & 22.33 & 0.90 \\
\hline CWV & 8.66 & $2.0 \%$ & -29.76 & 47.08 & 0.66 & 21.97 & $5.0 \%$ & -19.92 & 63.87 & 0.31 \\
\hline FGV & -0.06 & $-0.0 \%$ & -23.22 & 23.11 & 0.99 & -18.39 & $-7.5 \%$ & -44.82 & 8.04 & 0.18 \\
\hline TGV & -0.86 & $-0.7 \%$ & -9.81 & 8.09 & 0.85 & -3.15 & $-2.6 \%$ & -15.10 & 8.79 & 0.61 \\
\hline POGV & 7.17 & $2.6 \%$ & -20.49 & 34.82 & 0.62 & 19.98 & $7.2 \%$ & -13.54 & 53.49 & 0.61 \\
\hline VV & 6.24 & $100.0 \%$ & 3.29 & 9.20 & $<0.001^{* *}$ & 4.28 & $68.6 \%$ & -1.63 & 10.19 & 0.16 \\
\hline
\end{tabular}

Data were adjusted for age at MRI and whole brain volume (with the exception of WBV). The controls constitute the referent category.

** $p \leq 0.01$.

using ratios of corpus callosum measures to total midsagittal brain area (data not shown).

\section{Area Measures of the Cerebellar Vermis}

The adjusted mean midsagittal areas of the cerebellar vermis and 3 groups of lobules were calculated for each group (Table 6), and all measures were reduced in SSC patients compared with controls, with differences ranging between less than $1 \%$ and $17 \%$ (Tables 7-9). The greatest difference between SSC patients and controls was observed in the area of lobules VI-VII (11\%, absolute difference 3.9 $\mathrm{cm}^{2}, 95 \%$ CI -7.38 to $\left.-0.45, \mathrm{p}=0.03\right)$, particularly in the metopic subgroup relative to controls (17\%, absolute difference $3.0 \mathrm{~cm}^{2}, 95 \% \mathrm{CI}-9.9$ to $\left.-1.8, \mathrm{p}=0.01\right)$. Differences in total vermis area and area of lobules I-V and VIII-X between SSC patients and controls ranged from 3\% to 5\%, with wide confidence intervals ( $p$ values $>0.05$ ). There were no significant differences in cerebellar vermis areas between the sagittal subgroup and controls or between the sagittal and metopic subgroups, with differences ranging between $1 \%$ and $7 \%$ ( $\mathrm{p}$ values $>0.05$ across measures).

\section{Discussion}

The relation between skull dysmorphology and neural

TABLE 5. Adjusted group differences in mean brain volumes $\left(\mathrm{cm}^{3}\right)$ for children with SSC, by diagnosis (sagittal, metopic)

\begin{tabular}{|c|c|c|c|c|c|}
\hline \multirow[b]{3}{*}{ Variable } & \multicolumn{5}{|c|}{ Metopic vs Sagittal } \\
\hline & \multicolumn{2}{|c|}{ Mean Difference } & \multicolumn{2}{|c|}{$95 \% \mathrm{Cl}$} & \multirow{2}{*}{$\begin{array}{c}p \\
\text { Value }\end{array}$} \\
\hline & Absolute & $\%$ & LB & UB & \\
\hline WBV & 10.28 & $0.6 \%$ & -128.74 & 149.31 & 0.89 \\
\hline CGV & -11.24 & $-2.4 \%$ & -38.22 & 15.74 & 0.42 \\
\hline CWV & 11.60 & $0.4 \%$ & -17.35 & 40.55 & 0.44 \\
\hline FGV & -19.94 & $-7.3 \%$ & -48.24 & 8.36 & 0.18 \\
\hline TGV & -3.52 & $-3.1 \%$ & -17.22 & 10.18 & 0.62 \\
\hline POGV & -12.22 & $1.3 \%$ & -20.15 & 44.59 & 0.47 \\
\hline VV & -1.60 & $-8.6 \%$ & -7.66 & 4.47 & 0.61 \\
\hline
\end{tabular}

Data were adjusted for age at MRI and whole brain volume (with the exception of WBV). The sagittal synostosis subgroup constitutes the referent category. development in SSC is poorly understood and has received little attention, particularly in longer-term follow-up studies of surgery outcomes. Historically, investigators have assumed a scenario in which calvarial abnormality in SSC produces secondary brain deformation (abnormally shaped brain structure) or increased intracranial pressure. ${ }^{5,13,21,23,27,48}$ An alternative has been proposed in which craniosynostosis is associated with primary neuropathology or brain malformation. ${ }^{2,4,8,43}$ These 2 possibilities are not mutually exclusive: even if there were a common cause of craniosynostosis and brain dysmorphology, calvarial abnormality could also adversely affect brain development (i.e., both malformation and deformation of the brain have occurred). The potential influence of surgical intervention on these hypothesized causal pathways is also unclear, particularly in older patients. Observed abnormalities in the brains of children with SSC several years after surgery would seem to support the malformation hypothesis; i.e., the brain has followed an abnormal growth trajectory even after the potential constraint of the dysmorphic cranium has been presumably relieved. Conversely, a lack of abnormalities among patients (i.e., lack of case-control group differences) might suggest that brain dysmorphology prior to surgery is indeed associated with constraint of the dysmorphic cranium (i.e., deformation), with cranioplasty allowing a normal neural growth trajectory. However, it is also possible that cranial dysmorphology produces a permanent change in brain architecture prior to surgery that is unrelieved by cranial vault expansion or cranioplasty was not performed early enough to achieve this effect.

One implication of the brain deformation hypothesis is that areas of restricted growth in proximity to the fused suture will benefit from release of the suture during reconstructive surgery, promoting normal brain growth. A number of previous studies have described both qualitative and quantitative differences in the shape of the brain in SSC that mirror the shape of the skull prior to surgery ${ }^{2-4,45,65}$ (Marsh J, et al: Brain tomographic dysmorphology in nonsyndromic craniosynostosis. Presented at the Fifty-Fourth Annual Meeting of the American Cleft Palate-Craniofacial Association, April 1997, New Orleans), and others have described additional differences that do not correspond to regions of skull abnormality. ${ }^{2,4}$ Similar studies of brain 
TABLE 6. Adjusted mean midsagittal areas $\left(\mathrm{cm}^{2}\right)$ for children with and without SSC

\begin{tabular}{ccccc}
\hline Variable & Controls $(n=26)$ & SSC $($ all, $n=35)$ & Sagittal $(n=20)$ & Metopic $(n=15)$ \\
\hline Corpus callosum & & & & \\
\hline Total area & $56.72 \pm 10.13$ & $53.46 \pm 9.60$ & $54.18 \pm 10.15$ & $52.50 \pm 9.07$ \\
\hline CC S1 & $17.40 \pm 3.75$ & $17.36 \pm 3.13$ & $17.77 \pm 3.17$ & $16.80 \pm 3.08$ \\
\hline CC S2 & $9.55 \pm 2.34$ & $8.56 \pm 2.30$ & $8.54 \pm 2.23$ & $8.57 \pm 2.47$ \\
\hline CC S3 & $7.20 \pm 1.24$ & $6.92 \pm 1.57$ & $6.95 \pm 1.71$ & $6.89 \pm 1.41$ \\
\hline CC S4 & $6.82 \pm 2.26$ & $6.89 \pm 1.58$ & $6.99 \pm 1.51$ & $6.77 \pm 1.71$ \\
\hline CC S5 & $15.80 \pm 2.45$ & $13.77 \pm 2.99$ & $14.00 \pm 3.31$ & $13.47 \pm 2.57$ \\
\hline Cerebellar vermis & & & & $108.91 \pm 14.55$ \\
\hline Total area & $113.92 \pm 12.97$ & $107.42 \pm 14.06$ & $106.30 \pm 13.95$ & $46.80 \pm 6.81$ \\
\hline Lobules I-V & $48.20 \pm 6.42$ & $46.26 \pm 6.02$ & $45.85 \pm 5.50$ & $26.17 \pm 5.16$ \\
\hline Lobules VI-VII & $30.06 \pm 4.44$ & $27.33 \pm 5.77$ & $28.20 \pm 6.18$ & $35.97 \pm 5.33$ \\
\hline Lobules VIII-X & $35.71 \pm 5.04$ & $33.88 \pm 5.65$ & $32.31 \pm 5.49$ & \\
\hline
\end{tabular}

$\mathrm{CC}=$ corpus callosum; $\mathrm{S} 1$ = segment $1 ; \mathrm{S} 2$ = segment $2 ; \mathrm{S} 3$ = segment $3 ; \mathrm{S} 4$ = segment $4 ; \mathrm{S} 5$ = segment 5 .

Data were adjusted for age at MRI and total midsagittal brain area. Mean values are presented with standard deviations.

shape in postoperative sagittal craniosynostosis measured within 12 months following surgery have demonstrated that brain shape differs from both brain shape in controls and from preoperative brain shape. ${ }^{3}$ Maltese et al..$^{39}$ found that the intracranial volume anterior to the coronal sutures is reduced in patients with metopic craniosynostosis both before surgery and at follow-up at the age of 3 years. The present study is the first to measure size of the component gray and white matter of the brain in children with SSC and to further divide these measures by cerebral lobe. We did not find differences in measures of cerebral cortical gray matter and white matter, either overall or by region in school-aged children with metopic or sagittal craniosynostosis, consistent with the brain deformation hypothesis.

TABLE 7. Adjusted group differences in mean midsagittal areas $\left(\mathrm{cm}^{2}\right)$ for children with SSC affecting different sutures and children without (controls) craniosynostosis

\begin{tabular}{|c|c|c|c|c|c|}
\hline \multirow[b]{3}{*}{ Variable } & \multicolumn{5}{|c|}{ SSC vs Controls } \\
\hline & \multicolumn{2}{|c|}{ Mean Difference } & \multicolumn{2}{|c|}{$95 \% \mathrm{Cl}$} & \multirow{2}{*}{$\begin{array}{c}p \\
\text { Value }\end{array}$} \\
\hline & Absolute & $\%$ & LB & UB & \\
\hline \multicolumn{6}{|l|}{ Corpus callosum } \\
\hline Total area & -4.86 & $-7.3 \%$ & -9.69 & -0.03 & $0.05^{*}$ \\
\hline CC S1 & -0.98 & $-4.7 \%$ & -2.67 & 0.71 & 0.26 \\
\hline CC S2 & -0.93 & $-8.6 \%$ & -2.25 & 0.38 & 0.17 \\
\hline CC S3 & -0.43 & $-5.1 \%$ & -1.22 & 0.37 & 0.30 \\
\hline CC S4 & -0.17 & $-2.1 \%$ & -1.22 & 0.88 & 0.75 \\
\hline CC S5 & -2.34 & $-12.9 \%$ & -4.08 & -0.60 & $0.01^{* *}$ \\
\hline \multicolumn{6}{|l|}{ Cerebellar vermis } \\
\hline Total area & -6.77 & $-5.2 \%$ & -15.89 & 2.35 & 0.15 \\
\hline Lobules I-V & -1.67 & $-3.1 \%$ & -6.23 & 2.89 & 0.48 \\
\hline Lobules VI-VII & -3.92 & $-11.1 \%$ & -7.38 & -0.45 & $0.03^{*}$ \\
\hline Lobules VIII-X & -1.19 & $-3.0 \%$ & -4.41 & 2.03 & 0.47 \\
\hline
\end{tabular}

Data were adjusted for age at MRI and midsagittal brain area. The controls constitute the referent category.

${ }^{*} p<0.05$.

** $p \leq 0.01$.
This result, along with the finding of no significant group differences in whole brain volume (WBV), suggests that although the shape of the brain in SSC may be different (at least in metopic and sagittal synostosis), these differences are not a consequence of differences in size, either overall or local to the fused suture.

In contrast to measures of brain tissue, we found that the volume of the ventricles is significantly greater in children with metopic or sagittal synostosis, particularly sagittal synostosis (Fig. 3). Previous studies of SSC prior to surgery have found clinically significant ventriculomegaly to be uncommon. ${ }^{17,20,37,38}$ However, none of these studies have quantified ventricular volume, relying on qualitative radiological assessment of ventricular size, which has been demonstrated to vary widely among raters. ${ }^{17,20,37,38}$ Notably, Collmann et al..$^{20}$ have stated that studies of SSC have used inconsistent definitions of what constitutes ventricular dilation beyond the normal range of variation. In a study of a rabbit model of bilateral coronal synostosis, FellowsMayle and colleagues ${ }^{26}$ demonstrated increases in lateral ventricle volumes of up to $87 \%$ as compared with littermates without synostosis. It is important to note that while the difference in ventricular volume we describe here is statistically significant and relatively large in magnitude, the clinical significance and implications of this difference are unclear. Two previous studies have quantified ventricular volume in normal pediatric individuals, with one finding a mean of $11.45 \mathrm{~cm}^{3}$ in children aged $1-10$ years, ${ }^{1}$ and the other a mean of $21.3 \mathrm{~cm}^{3}$ and a range of $6-34 \mathrm{~cm}^{3}$ in children aged 1-16 years. ${ }^{72}$ With the exception of a single patient with metopic synostosis, ventricular volumes in both our controls and SSC patients fall well within these reported ranges for normal pediatric samples (Table 2), with volumes in SSC patients trending toward the upper end of the normal range of variation.

It is possible that abnormal venous outflow in patients with SSC contributes to the larger ventricular size. CSF production is intimately associated with venous pressure, and changes in this dynamic may alter CSF volume and, hence, ventricular size.,.0,64 Additionally, several studies have described marked dilation of subarachnoid and other 
TABLE 8. Adjusted group differences in mean midsagittal areas $\left(\mathrm{cm}^{2}\right)$ for children with SSC affecting different sutures (sagittal, metopic) and children without (controls) craniosynostosis

\begin{tabular}{|c|c|c|c|c|c|c|c|c|c|c|}
\hline \multirow[b]{3}{*}{ Variable } & \multicolumn{5}{|c|}{ Sagittal vs Controls } & \multicolumn{5}{|c|}{ Metopic vs Controls } \\
\hline & \multicolumn{2}{|c|}{ Mean Difference } & \multicolumn{2}{|c|}{$95 \% \mathrm{Cl}$} & \multirow{2}{*}{$\begin{array}{c}p \\
\text { Value }\end{array}$} & \multicolumn{2}{|c|}{ Mean Difference } & \multicolumn{2}{|c|}{$95 \% \mathrm{Cl}$} & \multirow{2}{*}{$\begin{array}{c}p \\
\text { Value }\end{array}$} \\
\hline & Absolute & $\%$ & LB & UB & & Absolute & $\%$ & LB & UB & \\
\hline \multicolumn{11}{|l|}{ Corpus callosum } \\
\hline Total area & -3.66 & $-5.5 \%$ & -9.88 & 2.57 & 0.26 & -6.32 & $-9.5 \%$ & -12.03 & -0.60 & $0.04^{*}$ \\
\hline CC S1 & -0.53 & $-2.5 \%$ & -2.57 & 1.50 & 0.61 & -1.52 & $-7.2 \%$ & -3.59 & 0.55 & 0.16 \\
\hline CC S2 & -0.93 & $-8.6 \%$ & -2.53 & 0.66 & 0.26 & -0.93 & $-8.6 \%$ & -2.51 & 0.64 & 0.25 \\
\hline CC S3 & -0.37 & $-4.4 \%$ & -1.43 & 0.69 & 0.50 & -0.50 & $-5.9 \%$ & -1.48 & 0.48 & 0.32 \\
\hline CC S4 & 0.06 & $0.7 \%$ & -1.12 & 1.24 & 0.93 & -0.45 & $-5.5 \%$ & -1.79 & 0.90 & 0.52 \\
\hline CC S5 & -1.83 & $-10.1 \%$ & -4.00 & 0.34 & 0.10 & -2.95 & $-16.3 \%$ & -4.85 & -1.06 & $0.004^{* *}$ \\
\hline \multicolumn{11}{|l|}{ Cerebellar vermis } \\
\hline Total area & -6.19 & $-4.8 \%$ & -16.46 & 4.08 & 0.24 & -7.47 & $-5.7 \%$ & -18.51 & 3.58 & 0.19 \\
\hline Lobules I-V & -1.43 & $-2.6 \%$ & -6.21 & 3.35 & 0.56 & -1.96 & $-3.6 \%$ & -7.34 & 3.42 & 0.48 \\
\hline Lobules VI-VII & -2.29 & $-6.5 \%$ & -6.33 & 1.75 & 0.27 & -5.89 & $-16.7 \%$ & -9.93 & -1.84 & $0.01^{* *}$ \\
\hline Lobules VIII-X & -2.48 & $-6.2 \%$ & -6.34 & 1.38 & 0.21 & 0.37 & $0.9 \%$ & -3.55 & 4.29 & 0.85 \\
\hline
\end{tabular}

CSF spaces. ${ }^{14,15,20,28,38,61}$ Other studies have found differences in the shape of the ventricles both before and after surgery. ${ }^{2-4}$ Neither hypothesis described above (about brain growth in SSC) would necessarily predict differences in ventricular volume. However, increased volume of the ventricles several years following reconstructive surgery suggests an intrinsic difference in the growth of these structures that is likely unrelated to suture fusion. Additional studies focusing on cerebral blood flow, including CSF spaces and venous sinuses, are necessary to tease out this relationship.

The present study demonstrates a significantly smaller midsagittal area of the corpus callosum as a whole in sag-

TABLE 9. Adjusted group differences in mean midsagittal areas $\left(\mathrm{cm}^{2}\right)$ for children with SSC, by diagnosis (sagittal, metopic)

\begin{tabular}{|c|c|c|c|c|c|}
\hline \multirow[b]{3}{*}{ Variable } & \multicolumn{5}{|c|}{ Metopic vs Sagittal } \\
\hline & \multicolumn{2}{|c|}{ Mean Difference } & \multicolumn{2}{|c|}{$95 \% \mathrm{Cl}$} & \multirow{2}{*}{$\begin{array}{c}p \\
\text { Value }\end{array}$} \\
\hline & Absolute & $\%$ & LB & UB & \\
\hline \multicolumn{6}{|l|}{ Corpus callosum } \\
\hline Total area & -2.75 & $-4.3 \%$ & -9.75 & 4.25 & 0.45 \\
\hline CC S1 & -1.04 & $-5.1 \%$ & -3.39 & 1.30 & 0.39 \\
\hline CC S2 & 0.02 & $0.2 \%$ & -1.74 & 1.78 & 0.99 \\
\hline CC S3 & -0.07 & $-0.8 \%$ & -1.36 & 1.23 & 0.92 \\
\hline CC S4 & -0.50 & $-6.1 \%$ & -1.85 & 0.85 & 0.47 \\
\hline CC S5 & -1.23 & $-7.5 \%$ & -3.30 & 0.83 & 0.25 \\
\hline \multicolumn{6}{|l|}{ Cerebellar vermis } \\
\hline Total area & -1.87 & $-1.5 \%$ & -12.38 & 8.64 & 0.73 \\
\hline Lobules I-V & -0.74 & $-1.4 \%$ & -4.97 & 3.49 & 0.74 \\
\hline Lobules VI-VII & -3.67 & $-11.1 \%$ & -7.59 & 0.24 & 0.08 \\
\hline Lobules VIII-X & 2.54 & $6.8 \%$ & -2.09 & 7.18 & 0.29 \\
\hline
\end{tabular}

Data were adjusted for age at MRI and midsagittal brain area. The sagittal synostosis subgroup constitutes the referent category. ittal and metopic craniosynostosis patients as compared with controls. Previous qualitative assessments have noted anomalies of the corpus callosum in children with metopic synostosis. ${ }^{11}$ The midsagittal area of the most posterior segment of the corpus callosum (CC S5) is significantly smaller in SSC patients than in controls, particularly in metopic synostosis. The functional significance of these differences in the corpus callosum in SSC is unknown. However, in one recent study we observed children with SSC to have specific deficits in bimanual dexterity ${ }^{68} \mathrm{Bi}-$ manual dexterity is believed to require interhemispheric transfer, primarily through the corpus callosum. ${ }^{12,40}$ Two studies have reported positive correlations between bimanual dexterity and the size of the corpus callosum. ${ }^{46,67}$ Furthermore, similar differences in the morphology of the corpus callosum have been associated with deficits in a number of other domains. ${ }^{22,31,50,71}$ Given that the corpus callosum arises very early in fetal development, ${ }^{33,47,55}$ differences in this structure suggest an underlying pathological pattern of development of the corpus callosum in SSC, consistent with the brain malformation hypothesis.

Our findings also indicate that a localized region of the midsagittal cerebellar vermis (lobules VI-VII) is significantly smaller in patients with metopic and sagittal craniosynostosis than in controls, and specifically in metopic synostosis cases. Although Hukki et al. ${ }^{30}$ found a substantial number of cases of Chiari I malformation in association with sagittal and unicoronal craniosynostosis, there has been no specific evidence suggesting alterations in the cerebellar vermis in SSC. The combined facts that differences in the cerebellar vermis are observed many years after surgery and that they are localized to specific lobules rather than found across the entire structure suggest that the developmental pattern of this specific portion of the cerebellum differs, which is not consistent with an overall deformational force. 

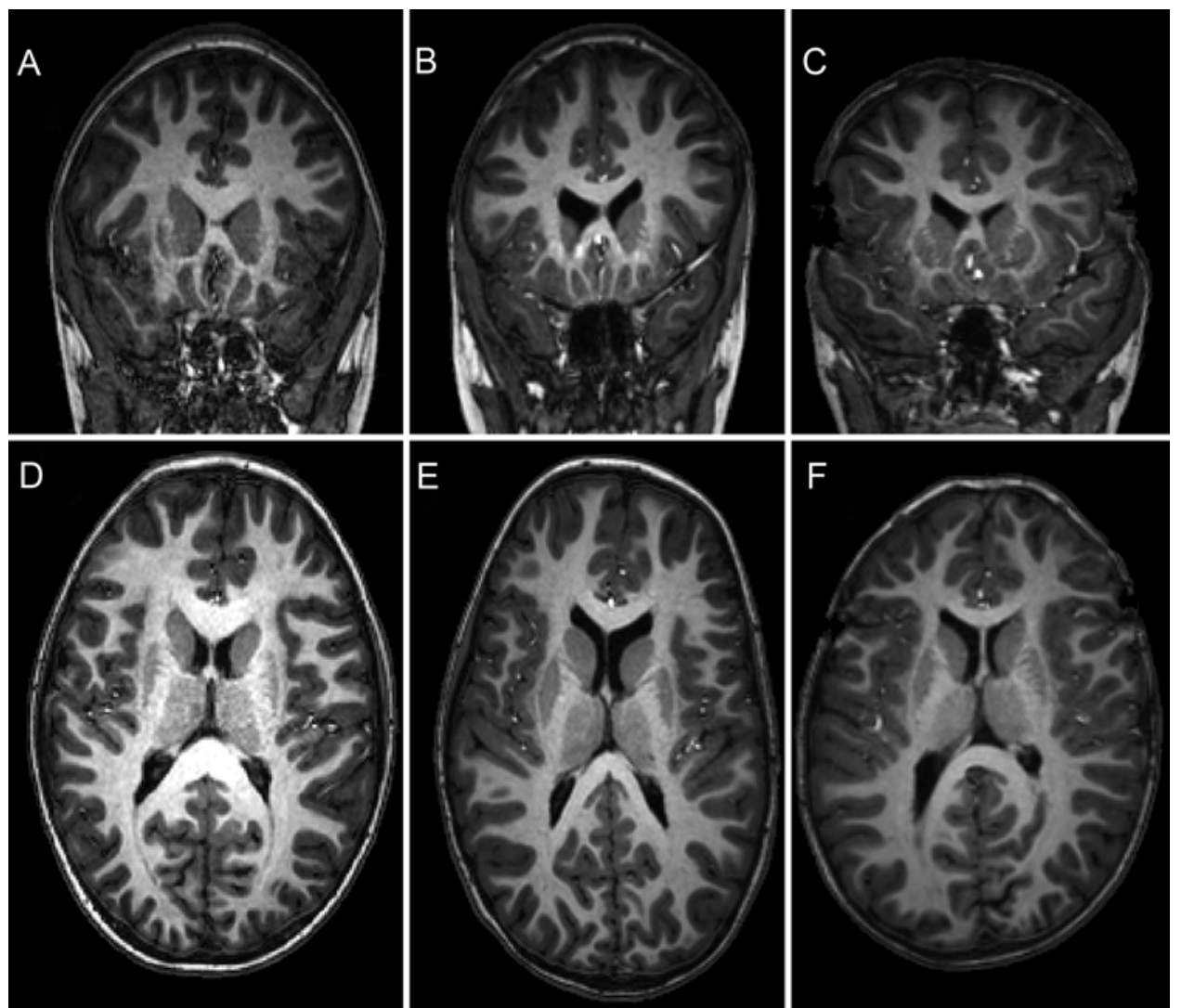

FIG. 3. Coronal $(A-C)$ and axial $(D-F)$ T1-weighted MPRAGE MR images obtained in representative participants from each of the 3 study groups, selected to illustrate the mean ventricular volume size for their respective study groups. The coronal slices were obtained through the genu of the corpus callosum. The axial slices were obtained at a plane through the genu and splenium of the corpus callosum. A and D: Images obtained in a control participant. B and E: Images obtained in a participant with sagittal synostosis. C and F: Images obtained in a participant with metopic synostosis.

The functional significance of these findings of smaller volumes for cerebellar lobules VI-VII in SSC is once again unclear, but damage to this region has been associated with deficits in learning, word fluency, ${ }^{51}$ reading, ${ }^{62}$ and learning motor sequences. ${ }^{42}$ Deficits in similar functional domains have been noted among children with SSC, $, 10,32$, $34,35,41,52-54,58,60,70$ but it remains to be tested whether these structural-functional relations also characterize children with SSC.

\section{Conclusions}

Collectively, our findings do not exclusively support the deformation or malformation hypothesis of brain growth in SSC. Rather, there is evidence supporting each of these hypotheses in different regions of the brain, suggesting that brain growth in children with metopic or sagittal synostosis may be affected both by deformational forces exerted by the dysmorphic skull and by an intrinsically different pattern of development marked by brain malformation. The present study also suggests that the elevated risk of neurodevelopmental deficits in children with metopic and sagittal synostosis is not likely associated with differences in overall brain size or regional differences in the size of the lobes of the cerebrum. Instead, we find localized differences between SSC patients and controls in the ventricles and in the midsagittal structures of the corpus callosum and the cerebellum. The functional significance of these differences is unclear, although abnormal patterns of neural connectivity have been previously noted in adolescents with isolated sagittal synostosis. ${ }^{8}$ Future studies assessing correlations among behavioral and anatomical measures are needed to determine whether these structure/function relationships are present in children with SSC. This work is currently underway in our lab, using measures from a comprehensive battery of neuropsychological tests..$^{56,68}$

\section{Acknowledgments}

We thank Sharman Conner for coordinating the research efforts of the study centers. We also thank the research study staff and the families who participated in this research.

This work was supported by a grant from the National Institute of Dental and Craniofacial Research (R01 DE 13813 awarded to Dr. Speltz).

\section{References}

1. Akdogan I, Kiroglu Y, Onur S, Karabuluti N: The volume fraction of brain ventricles to total brain volume: a computed tomography stereological study. Folia Morphol (Warsz) 69:193-200, 2010 
2. Aldridge K, Kane AA, Marsh JL, Panchal J, Boyadjiev SA, Yan P, et al: Brain morphology in nonsyndromic unicoronal craniosynostosis. Anat Rec A Discov Mol Cell Evol Biol 285:690-698, 2005

3. Aldridge K, Kane AA, Marsh JL, Yan P, Govier D, Richtsmeier JT: Relationship of brain and skull in pre- and postoperative sagittal synostosis. J Anat 206:373-385, 2005

4. Aldridge K, Marsh JL, Govier D, Richtsmeier JT: Central nervous system phenotypes in craniosynostosis. J Anat 201:31-39, 2002

5. Aoki N: Intracranial changes with unilateral coronal synostosis. Surg Neurol 22:249-252, 1984

6. Barta PE, Dhingra L, Royall R, Schwartz E: Improving stereological estimates for the volume of structures identified in three-dimensional arrays of spatial data. J Neurosci Methods 75:111-118, 1997

7. Becker DB, Petersen JD, Kane AA, Cradock MM, Pilgram TK, Marsh JL: Speech, cognitive, and behavioral outcomes in nonsyndromic craniosynostosis. Plast Reconstr Surg 116:400-407, 2005

8. Beckett JS, Brooks ED, Lacadie C, Vander Wyk B, Jou RJ, Steinbacher DM, et al: Altered brain connectivity in sagittal craniosynostosis. J Neurosurg Pediatr 13:690-698, 2014

9. Bellew M, Chumas P, Mueller R, Liddington M, Russell J: Pre- and postoperative developmental attainment in sagittal synostosis. Arch Dis Child 90:346-350, 2005

10. Bellew M, Liddington M, Chumas P, Russell J: Preoperative and postoperative developmental attainment in patients with sagittal synostosis: 5-year follow-up. J Neurosurg Pediatr 7:121-126, 2011

11. Bottero L, Lajeunie E, Arnaud E, Marchac D, Renier D: Functional outcome after surgery for trigonocephaly. Plast Reconstr Surg 102:952-960, 1998

12. Buse J, August J, Bock N, Dörfel D, Rothenberger A, Roessner V: Fine motor skills and interhemispheric transfer in treatment-naive male children with Tourette syndrome. Dev Med Child Neurol 54:629-635, 2012

13. Camfield PR, Camfield CS: Neurological aspects of craniosynostosis, in Cohen MM, MacLean RE (eds): Craniosynostosis: Diagnosis, Evaluation, and Management, ed 2. New York: Oxford University Press, 2000, pp 177-183

14. Carmel PW, Luken MG III, Ascherl GF Jr: Craniosynostosis: computed tomographic evaluation of skull base and calvarial deformities and associated intracranial changes. Neurosurgery 9:366-372, 1981

15. Chadduck WM, Chadduck JB, Boop FA: The subarachnoid spaces in craniosynostosis. Neurosurgery 30:867-871, 1992

16. Chieffo D, Tamburrini G, Massimi L, Di Giovanni S, Giansanti C, Caldarelli M, et al: Long-term neuropsychological development in single-suture craniosynostosis treated early. J Neurosurg Pediatr 5:232-237, 2010

17. Cinalli G, Sainte-Rose C, Kollar EM, Zerah M, Brunelle F, Chumas P, et al: Hydrocephalus and craniosynostosis. J Neurosurg 88:209-214, 1998

18. Cohen MM, MacLean RE (eds): Craniosynostosis: Diagnosis, Evaluation, and Management, ed 2. New York: Oxford University Press, 2000

19. Cohen SR, Cho DC, Nichols SL, Simms C, Cross KP, Burstein FD: American Society of Maxillofacial Surgeons Outcome Study: preoperative and postoperative neurodevelopmental findings in single-suture craniosynostosis. Plast Reconstr Surg 114:841-849, 2004

20. Collmann H, Sörensen N, Krauss J: Hydrocephalus in craniosynostosis: a review. Childs Nerv Syst 21:902-912, 2005

21. Da Costa AC, Anderson VA, Savarirayan R, Wrennall JA, Chong DK, Holmes AD, et al: Neurodevelopmental functioning of infants with untreated single-suture craniosynostosis during early infancy. Childs Nerv Syst 28:869-877, 2012
22. Dougherty RF, Ben-Shachar M, Deutsch GK, Hernandez A, Fox GR, Wandell BA: Temporal-callosal pathway diffusivity predicts phonological skills in children. Proc Natl Acad Sci U S A 104:8556-8561, 2007

23. Dufresne CR, McCarthy JG, Cutting CB, Epstein FJ, Hoffman WY: Volumetric quantification of intracranial and ventricular volume following cranial vault remodeling: a preliminary report. Plast Reconstr Surg 79:24-32, 1987

24. Eckert MA, Leonard CM, Richards TL, Aylward EH, Thomson J, Berninger VW: Anatomical correlates of dyslexia: frontal and cerebellar findings. Brain 126:482-494, 2003

25. Feise RJ: Do multiple outcome measures require p-value adjustment? BMC Med Res Methodol 2:8, 2002

26. Fellows-Mayle W, Hitchens TK, Simplaceanu E, Horner J, Barbano T, Nakaya K, et al: Age-related changes in lateral ventricle morphology in craniosynostotic rabbits using magnetic resonance imaging. Childs Nerv Syst 21:385-391, 2005

27. Fok H, Jones BM, Gault DG, Andar U, Hayward R: Relationship between intracranial pressure and intracranial volume in craniosynostosis. Br J Plast Surg 45:394-397, 1992

28. Hassler W, Zentner J: Radical osteoclastic craniectomy in sagittal synostosis. Neurosurgery 27:539-543, 1990

29. Hollingshead AB: Four Factor Index of Social Status. New Haven, CT: Yale University, 1975

30. Hukki A, Koljonen V, Karppinen A, Valanne L, Leikola J: Brain anomalies in 121 children with non-syndromic single suture craniosynostosis by MR imaging. Eur J Paediatr Neurol 16:671-675, 2012

31. Hynd GW, Semrud-Clikeman M, Lorys AR, Novey ES, Eliopulos D, Lyytinen H: Corpus callosum morphology in attention deficit-hyperactivity disorder: morphometric analysis of MRI. J Learn Disabil 24:141-146, 1991

32. Kapp-Simon KA, Speltz ML, Cunningham ML, Patel PK, Tomita T: Neurodevelopment of children with single suture craniosynostosis: a review. Childs Nerv Syst 23:269-281, 2007

33. Katz MJ, Lasek RJ, Silver J: Ontophyletics of the nervous system: development of the corpus callosum and evolution of axon tracts. Proc Natl Acad Sci U S A 80:5936-5940, 1983

34. Kini U, Hurst JA, Byren JC, Wall SA, Johnson D, Wilkie AOM: Etiological heterogeneity and clinical characteristics of metopic synostosis: Evidence from a tertiary craniofacial unit. Am J Med Genet A 152A:1383-1389, 2010

35. Korpilahti P, Saarinen P, Hukki J: Deficient language acquisition in children with single suture craniosynostosis and deformational posterior plagiocephaly. Childs Nerv Syst 28:419-425, 2012

36. Kweldam CF, van der Vlugt JJ, van der Meulen JJNM: The incidence of craniosynostosis in the Netherlands, 1997-2007. J Plast Reconstr Aesthet Surg 64:583-588, 2011

37. Lee SS, Duncan CC, Knoll BI, Persing JA: Intracranial compartment volume changes in sagittal craniosynostosis patients: influence of comprehensive cranioplasty. Plast Reconstr Surg 126:187-196, 2010

38. Magge KT, Magge SN, Keating RF, Myseros JS, Boyajian MJ, Sauerhammer TM, et al: Incidental findings on preoperative computed tomography for nonsyndromic single suture craniosynostosis. J Craniofac Surg 25:1327-1330, 2014

39. Maltese G, Tarnow P, Wikberg E, Bernhardt P, Lagerlöf JH, Tovetjärn R, et al: Intracranial volume before and after surgical treatment for isolated metopic synostosis. J Craniofac Surg 25:262-266, 2014

40. Margolis A, Donkervoort M, Kinsbourne M, Peterson BS: Interhemispheric connectivity and executive functioning in adults with Tourette syndrome. Neuropsychology 20:66-76, 2006

41. Mendonca DA, White N, West E, Dover S, Solanki G, Nishikawa $\mathrm{H}$ : Is there a relationship between the severity of 
metopic synostosis and speech and language impairments? J Craniofac Surg 20:85-89, 2009

42. Menghini D, Hagberg GE, Caltagirone C, Petrosini L, Vicari S: Implicit learning deficits in dyslexic adults: an fMRI study. Neuroimage 33:1218-1226, 2006

43. Moss ML, Young RW: A functional approach to craniology. Am J Phys Anthropol 18:281-292, 1960

44. Naumann HL, Haberkern CM, Pietila KE, Birgfeld CB, Starr JR, Kapp-Simon KA, et al: Duration of exposure to cranial vault surgery: associations with neurodevelopment among children with single-suture craniosynostosis. Paediatr Anaesth 22:1053-1061, 2012

45. Proudman TW, Clark BE, Moore MH, Abbott AH, David DJ: Central nervous system imaging in Crouzon's syndrome. J Craniofac Surg 6:401-405, 1995

46. Rademaker KJ, Lam JNGP, Van Haastert IC, Uiterwaal CSPM, Lieftink AF, Groenendaal F, et al: Larger corpus callosum size with better motor performance in prematurely born children. Semin Perinatol 28:279-287, 2004

47. Rakic P, Yakovlev PI: Development of the corpus callosum and cavum septi in man. J Comp Neurol 132:45-72, 1968

48. Renier D, Sainte-Rose C, Marchac D, Hirsch JF: Intracranial pressure in craniostenosis. J Neurosurg 57:370-377, 1982

49. Rothman KJ: Six persistent research misconceptions. J Gen Intern Med 29:1060-1064, 2014

50. Sammler D, Kotz SA, Eckstein K, Ott DVM, Friederici AD: Prosody meets syntax: the role of the corpus callosum. Brain 133:2643-2655, 2010

51. Schmitt JE, Eliez S, Warsofsky IS, Bellugi U, Reiss AL: Enlarged cerebellar vermis in Williams syndrome. J Psychiatr Res 35:225-229, 2001

52. Shimoji T, Shimabukuro S, Sugama S, Ochiai Y: Mild trigonocephaly with clinical symptoms: analysis of surgical results in 65 patients. Childs Nerv Syst 18:215-224, 2002

53. Shipster C, Hearst D, Somerville A, Stackhouse J, Hayward $\mathrm{R}$, Wade A: Speech, language, and cognitive development in children with isolated sagittal synostosis. Dev Med Child Neurol 45:34-43, 2003

54. Sidoti EJ Jr, Marsh JL, Marty-Grames L, Noetzel MJ: Longterm studies of metopic synostosis: frequency of cognitive impairment and behavioral disturbances. Plast Reconstr Surg 97:276-281, 1996

55. Silver J, Lorenz SE, Wahlsten D, Coughlin J: Axonal guidance during development of the great cerebral commissures: descriptive and experimental studies, in vivo, on the role of preformed glial pathways. J Comp Neurol 210:10-29, 1982

56. Speltz ML, Collett BR, Wallace ER, Starr JR, Cradock MM, Buono L, et al: Intellectual and academic functioning of school-age children with single-suture craniosynostosis. Pediatrics 135:e615-e623, 2015

57. Speltz ML, Kapp-Simon K, Collett B, Keich Y, Gaither R, Cradock MM, et al: Neurodevelopment of infants with singlesuture craniosynostosis: presurgery comparisons with casematched controls. Plast Reconstr Surg 119:1874-1881, 2007

58. Starr JR, Collett BR, Gaither R, Kapp-Simon KA, Cradock MM, Cunningham ML, et al: Multicenter study of neurodevelopment in 3-year-old children with and without single-suture craniosynostosis. Arch Pediatr Adolesc Med 166:536-542, 2012

59. Starr JR, Kapp-Simon KA, Cloonan YK, Collett BR, Cradock MM, Buono L, et al: Presurgical and postsurgical assessment of the neurodevelopment of infants with singlesuture craniosynostosis: comparison with controls. J Neurosurg 107 (2 Suppl):103-110, 2007

60. Starr JR, Lin HJ, Ruiz-Correa S, Cunningham ML, Ellenbogen RG, Collett BR, et al: Little evidence of association between severity of trigonocephaly and cognitive development in infants with single-suture metopic synostosis. Neurosurgery 67:408-416, 2010
61. Steinbok P: Incidental findings on preoperative computed tomography for nonsyndromic single-suture craniosynostosis by Magge et al. J Craniofac Surg 26:328-329, 2015

62. Steinlin M: Cerebellar disorders in childhood: cognitive problems. Cerebellum 7:607-610, 2008

63. Strahle J, Muraszko KM, Buchman SR, Kapurch J, Garton HJL, Maher CO: Chiari malformation associated with craniosynostosis. Neurosurg Focus 31(3):E2, 2011

64. Thompson DN, Malcolm GP, Jones BM, Harkness WJ, Hayward RD: Intracranial pressure in single-suture craniosynostosis. Pediatr Neurosurg 22:235-240, 1995

65. Tokumaru AM, Barkovich AJ, Ciricillo SF, Edwards MS: Skull base and calvarial deformities: association with intracranial changes in craniofacial syndromes. AJNR Am J Neuroradiol 17:619-630, 1996

66. Tubbs RS, Elton S, Blount JP, Oakes WJ: Preliminary observations on the association between simple metopic ridging in children without trigonocephaly and the Chiari I malformation. Pediatr Neurosurg 35:136-139, 2001

67. van Kooij BJM, van Handel M, Uiterwaal CSPM, Groenendaal F, Nievelstein RAJ, Rademaker KJ, et al: Corpus callosum size in relation to motor performance in 9- to 10 -year-old children with neonatal encephalopathy. Pediatr Res 63:103-108, 2008

68. Wallace ER, Collett BR, Kapp-Simon K, Starr JR, Birgfeld C, Speltz ML: Visuomotor function in school-age children with single-suture craniosynostosis. J Dev Behav Pediatr 37:483-490, 2016

69. Warren SM, Proctor MR, Bartlett SP, Blount JP, Buchman SR, Burnett W, et al: Parameters of care for craniosynostosis: craniofacial and neurologic surgery perspectives. Plast Reconstr Surg 129:731-737, 2012

70. Warschausky S, Angobaldo J, Kewman D, Buchman S, Muraszko KM, Azengart A: Early development of infants with untreated metopic craniosynostosis. Plast Reconstr Surg 115:1518-1523, 2005

71. Westerhausen R, Luders E, Specht K, Ofte SH, Toga AW, Thompson PM, et al: Structural and functional reorganization of the corpus callosum between the age of 6 and 8 years. Cereb Cortex 21:1012-1017, 2011

72. Xenos C, Sgouros S, Natarajan K: Ventricular volume change in childhood. J Neurosurg 97:584-590, 2002

\section{Disclosures}

The authors report no conflict of interest concerning the materials or methods used in this study or the findings specified in this paper.

\section{Author Contributions}

Conception and design: Aldridge, Collett, Birgfeld, Kapp-Simon, Aylward, Cunningham, Speltz. Acquisition of data: Aldridge, Collett, Birgfeld, Austin, Yeh, Feil, Aylward, Cunningham, Speltz. Analysis and interpretation of data: Aldridge, Collett, Wallace, Austin, Kapp-Simon, Aylward, Speltz. Drafting the article: Aldridge, Wallace, Aylward, Speltz. Critically revising the article: Aldridge, Collett, Wallace, Birgfeld, Kapp-Simon, Aylward, Cunningham, Speltz. Reviewed submitted version of manuscript: all authors. Approved the final version of the manuscript on behalf of all authors: Aldridge. Statistical analysis: Wallace.

\section{Correspondence}

Kristina Aldridge, University of Missouri School of Medicine, Department of Pathology \& Anatomical Sciences, One Hospital Dr., M309 Med Sci Bldg., Columbia, MO 65212. email: aldridgek@missouri.edu. 